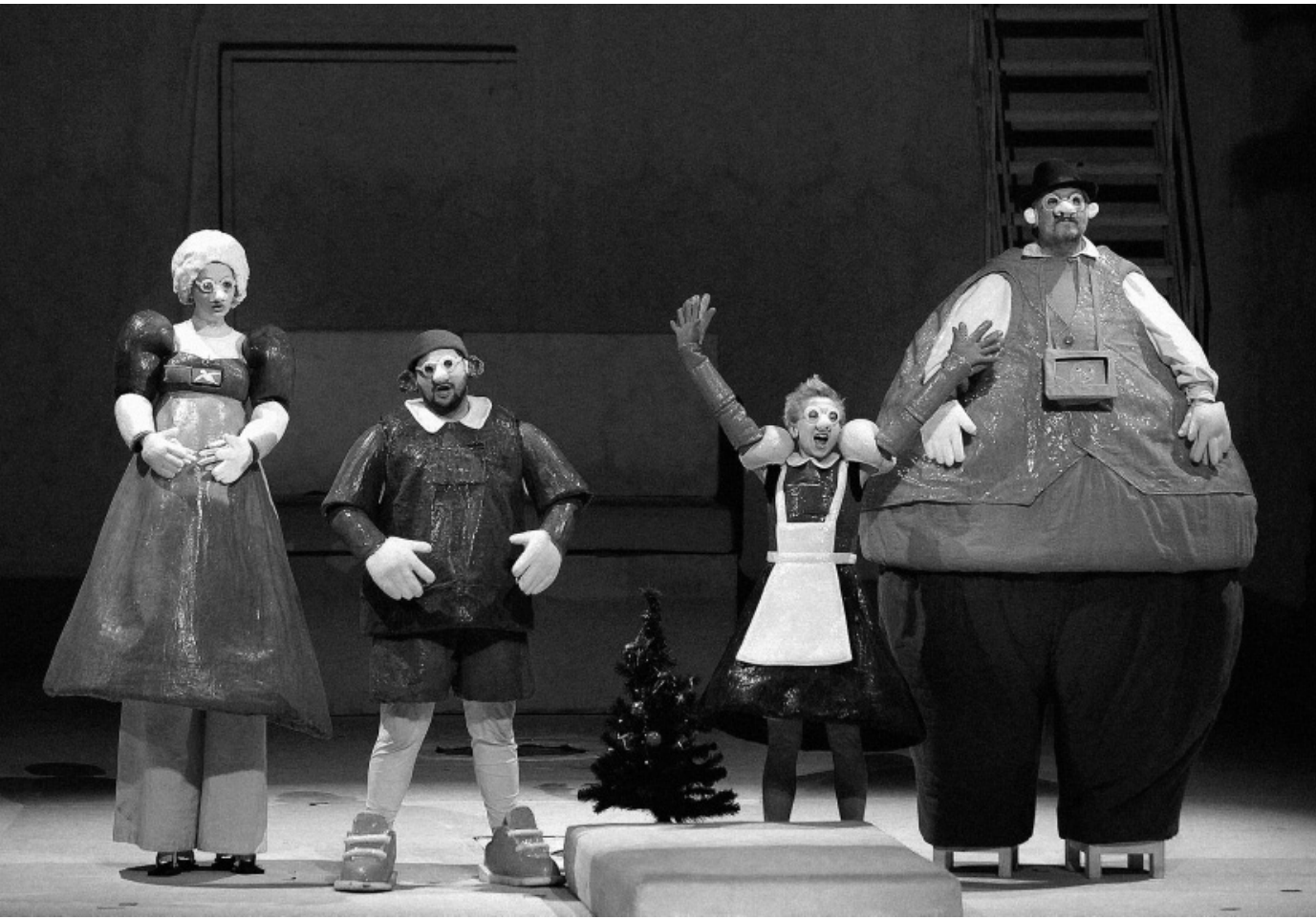

\title{
Prémios e premiados em São Petersburgo
}

\section{Rita Martins}

Fundada em 1703, a cidade de Pedro, o Grande, suscita admiração, até mesmo respeito, e, se não fosse pela imponente arquitectura dos seus palácios, seria pelas figuras que percorreram as suas avenidas, tais como Gogol, Dostoievski e Tchaikovski. No centro da longa Avenida Nevski encontra-se o Teatro Alexandrinski, espaço emblemático das artes cénicas. Ai, Tchekov conheceu o desespero com o malogro da estreia de A gaivota (1896) e Meyerhold alcançou o reconhecimento com a encenação de Dom João de Molière (1900). Para celebrar este ofício de risco, tantas vezes ingrato, a enorme sala dourada e vermelha acolheu, no dia 17 de Abril de 2011, os participantes da XIV edição do Prémio Europa de Teatro e da XII edição do Prémio Europa Novas Realidades Teatrais.

Criado em 1986, com o apoio da Comunidade Europeia, o primeiro Prémio Europa foi entregue a Ariane Mnouchkine, em 1987, no Anfiteatro Grego de Taormina. Nesse ano, ainda o muro de Berlim dividia o continente, Mnouchkine dedicou o prémio aos artistas de Leste. Duas décadas mais tarde, uma Europa em crise debate-se com as desigualdades económicas, mas, São Petersburgo é a cidade anfitriã e Peter Stein, nascido em 1937 sob o regime nazi, é o galardoado. A complexidade dos movimentos históricos, entre a utopia e o fracasso, a tensão entre a realidade e a esperança, são ideias debatidas por Stein, cuja primeira encenação remonta a 1967, com Salvo de Edward Bond (Bremen). A extrema atenção aos textos e ao enquadramento histórico conflui num teatro crítico onde, segundo Peter Iden, "as tragédias optimistas aparecem, igualmente, como tragédias do optimismo" (Iden 2001: 66). A sua longa e proficua carreira internacional, a ousadia e rigor com que tem encenado textos antigos e contemporâneos, justificam o prestígio dum encenador que mostra, através dos actores, e citando Shakespeare, "breves crónicas do tempo".

De 1970 a 1985, na direcção da Schaubühne de Berlim, Stein pôs em cena peças de Ibsen, Gorki, Botho Strauss, Peter Handke. Embora se tenha esbatido o radicalismo político dos anos 60 e 70, o arrojo cénico ficou, desde essa altura, associado ao seu nome: a Oresteia de Ésquilo teve 12 horas de duração (Berlim, 1980), ou, já em 2000, o Fausto / e // de Goethe (Hanôver) foi representado, na integra, durante 20 horas, integrou 35 intérpretes e levou dois anos a preparar. A relação com a actriz italiana Maddalena Crippa levou Stein a mudar-se para Itália no início dos anos 90, onde vive desde então. Tem trabalhado com elencos de diversas nacionalidades - italiana, britânica, russa e alemã - em produções que têm sido apresentadas por toda a Europa. Ainda o ano passado, Édipo em Colono de Sófocles, protagonizado por Klaus Maria Brandauer, teve ovações por parte do público do Festival de Salzburg. Em São Petersburgo, na semana do Prémio Europa, o prestigiado actor austríaco voltou a actuar sob a direcção de Peter Stein em A bilha quebrada de Kleist.

Embora seja sempre possivel lamentar os esquecimentos, o Prémio Europa, que distingue artistas com carreiras

\section{Rita Martins}

é critica de teatro e investigadora do Centro de Estudos de Teatro da Faculdade de Letras, Universidade de Lisboa. Organizou em 2006 o livro Teatro completo, de D. João da Câmara, e publicou em 2007 o estudo Raul Brandão: Do texto à cena, ambos editados pela Imprensa Nacional - Casa da Moeda. 


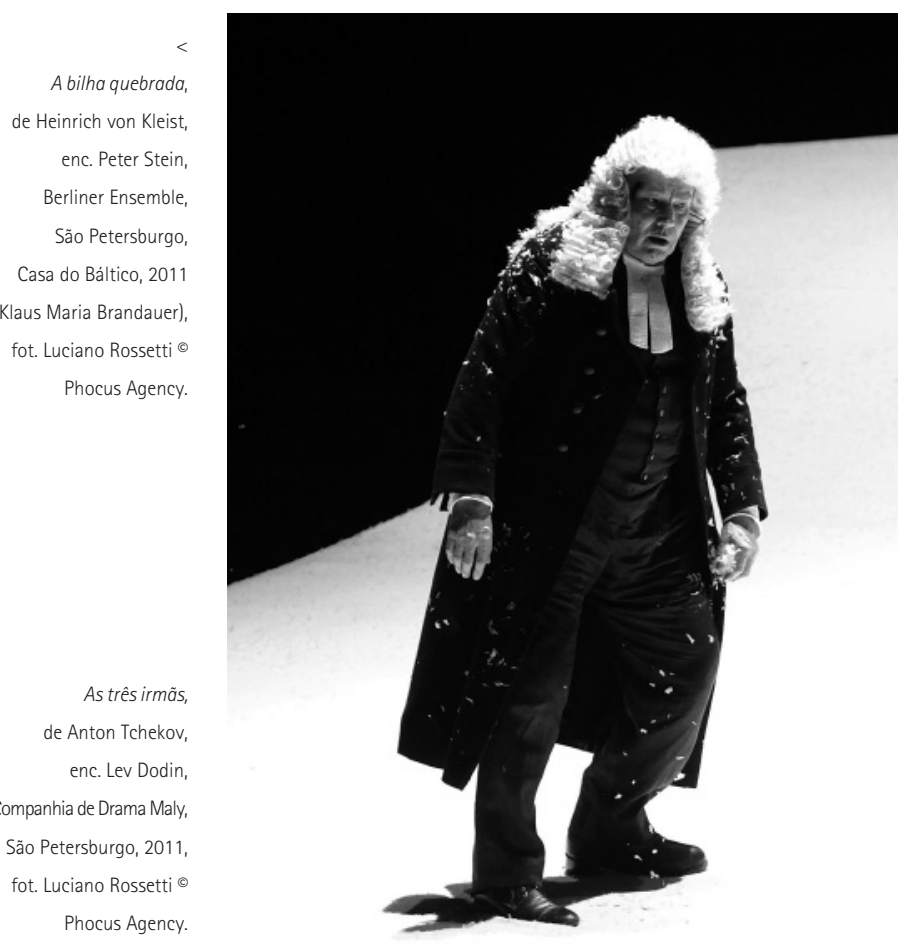

Phocus Agency.

0 teatro,

enc. Viliam Docolomansk Teatro Estúdio Farm in the

Cave, São Petersburgo,

Teatro Público Joven 2011, fot. Luciano Rossett

๑ Phocus Agency.

consagradas a nivel internacional, tem sido entregue a personalidades incontornáveis, que marcaram o teatro de forma indiscutivel (Peter Brook, Pina Bausch, Giorgio Strehler, Heiner Müller, Harold Pinter, entre outros).

A partir da III edição, é fundado o Prémio Europa Novas Realidades Teatrais, que considera "a totalidade do trabalho do candidato, o seu carácter inovador e a sua originalidade." A excelente iniciativa, que, de facto, serve de estímulo às tendências emergentes do teatro europeu, deixa em suspenso a interrogação sobre o conceito "originalidade" e levanta a questão - haverá algo de novo debaixo do sol? Especulações teóricas à parte, destacamos com orgulho a presença do Teatro Meridional, a primeira companhia portuguesa a receber o prémio, ao lado de Viliam Docolomanský (República Checa), Katie Mitchell (ReinoUnido), Andrey Moguchiy (Rússia), Kristian Smeds (Finlândia) e o Vesturport Theatre (Islândia). Durante seis dias, críticos de todo o mundo tentaram acompanhar os quinze espectáculos programados e, ainda, as dez conferências que reuniram investigadores, criticos e artistas premiados. Katie Mitchell foi a única que não conseguiu levar as suas produções a São Petersburgo.

No que diz respeito aos espectáculos, embora fossem apenas uma pequena amostra do percurso destes criadores não houve grandes revelações ou rasgos de "originalidade" - encenações bem executadas, actores competentes, cuja interpretação revelava a diversidade de escolas e tradições e algumas cenografias espantosas. Há que salientar, porém a qualidade e consistência dos projectos, assim como a sua relevância nos respectivos países. Docolomanský, atento às minorias e às identidades nacionais, explora a expressão humana através do teatro-dança, enraizando a pesquisa física em tradições e rituais. SCLAVI / A canção de um emigrante, resultado de uma investigação de campo sobre a emigração eslovaca, foi aclamado pela crítica, ganhou prémios e catapultou Farm in the Cave, grupo fundado por Docolomanský em 2001, para o panorama

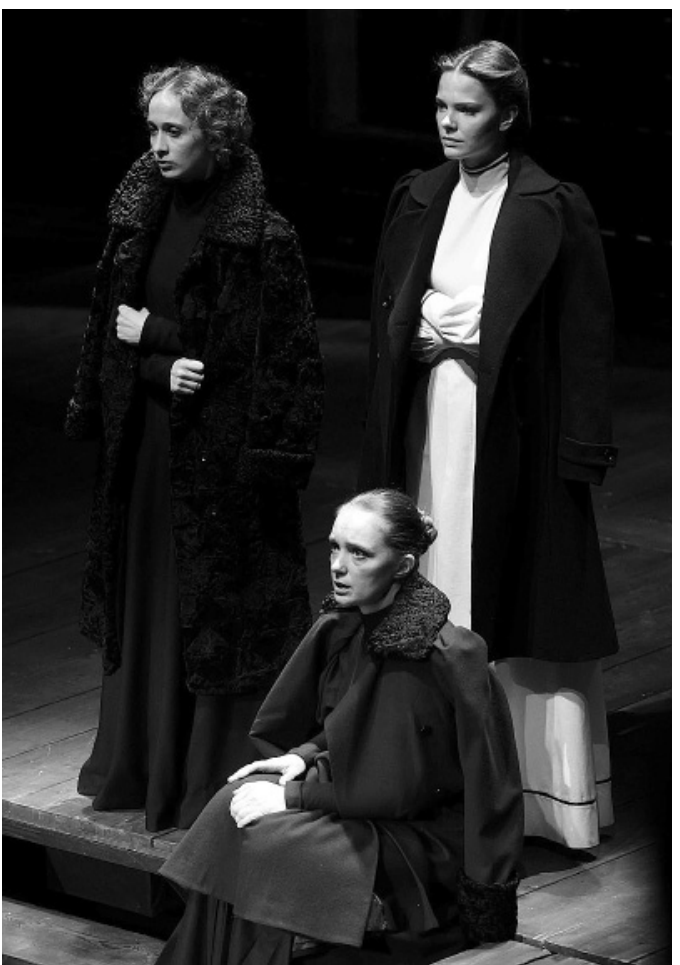

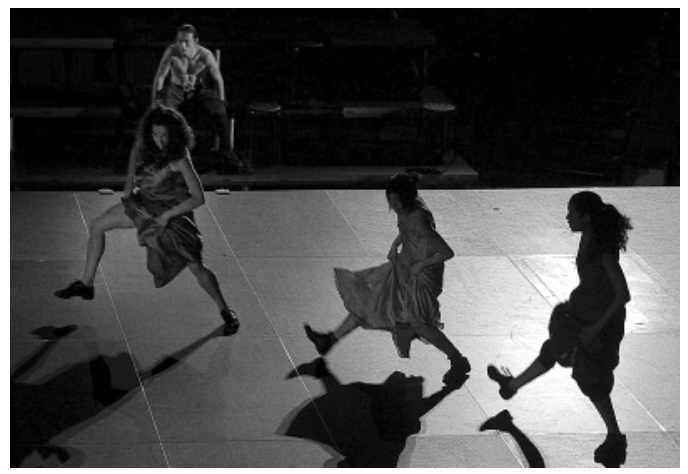

internacional ${ }^{1}$. Em São Petersburgo foram apresentados A viagem (uma súmula dos trabalhos da companhia) e O teatro, onde a exuberância dos ritmos brasileiros figura em tensões e provocações nos corpos intensos dos intérpretes, à procura de um espaço de liberdade e de uma razão de ser.

As pesquisas e o foco na fisicalidade do actor mostram afinidades entre Farm in the Cave e o projecto Províncias do Teatro Meridional. Dirigida por Miguel Seabra e Natália Luiza, a companhia é distinguida pela qualidade artística de trabalhos que cuidam da palavra e do gesto, pondo em cena textos dramáticos, literários e tradições orais, filtrados por uma fina sensibilidade antropológica e humana. Cabo-Verde, de 2007, e a mais recente produção 1974, estiveram em cena num envelhecido Teatro Komissarzhevskaya. 0 primeiro, sendo um bom exemplo do trabalho do grupo, contrasta com o segundo, que muito se afasta dos processos e linhas temáticas que definem o Teatro Meridional.

Nos antípodas destes dois colectivos poderíamos colocar a companhia islandesa, conhecida em Londres e apreciada pela crítica inglesa, mais concretamente por Michael Billington, moderador da conferência/encontro com o Vesturport Theatre. Muito bem acompanhada pela 


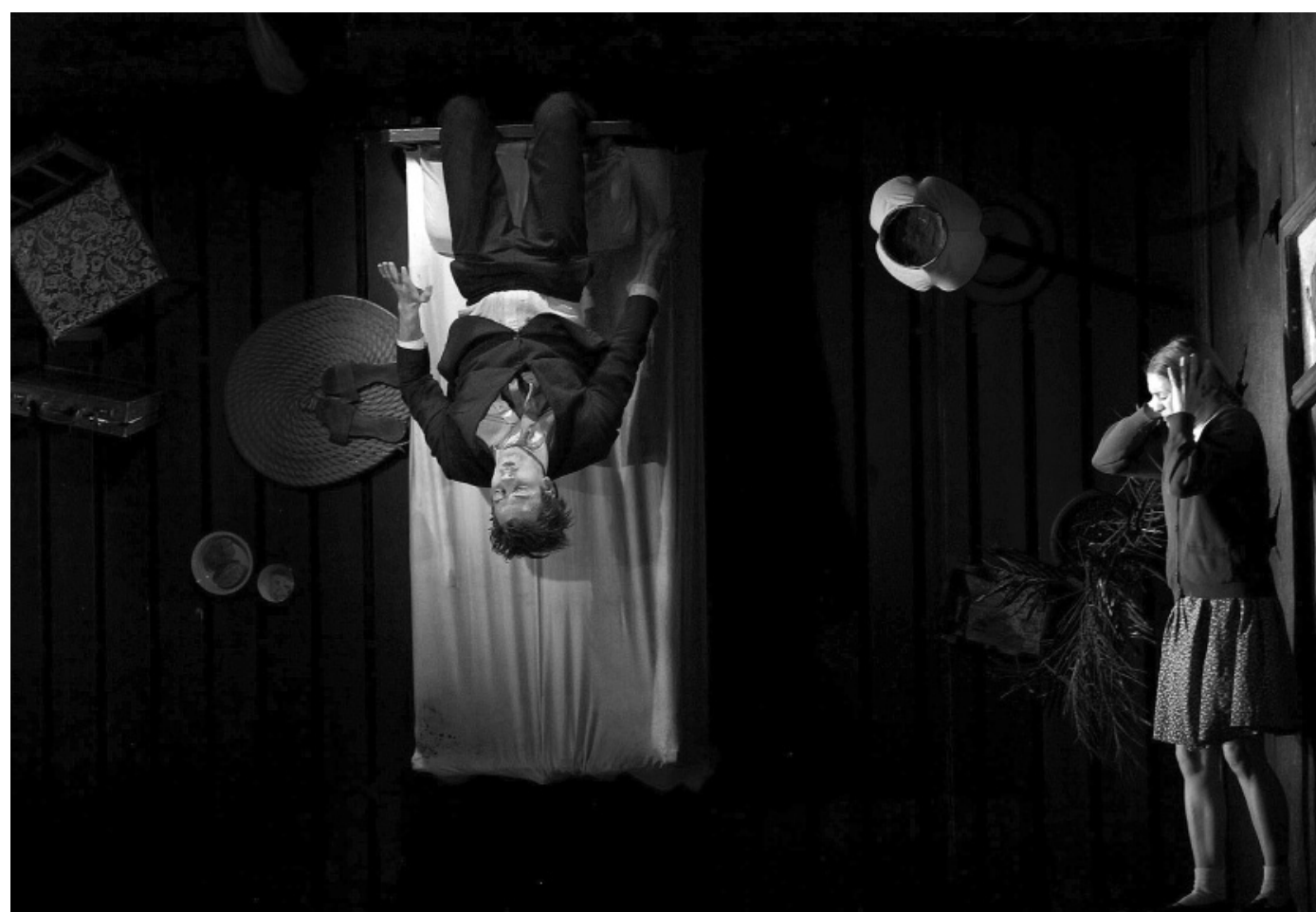

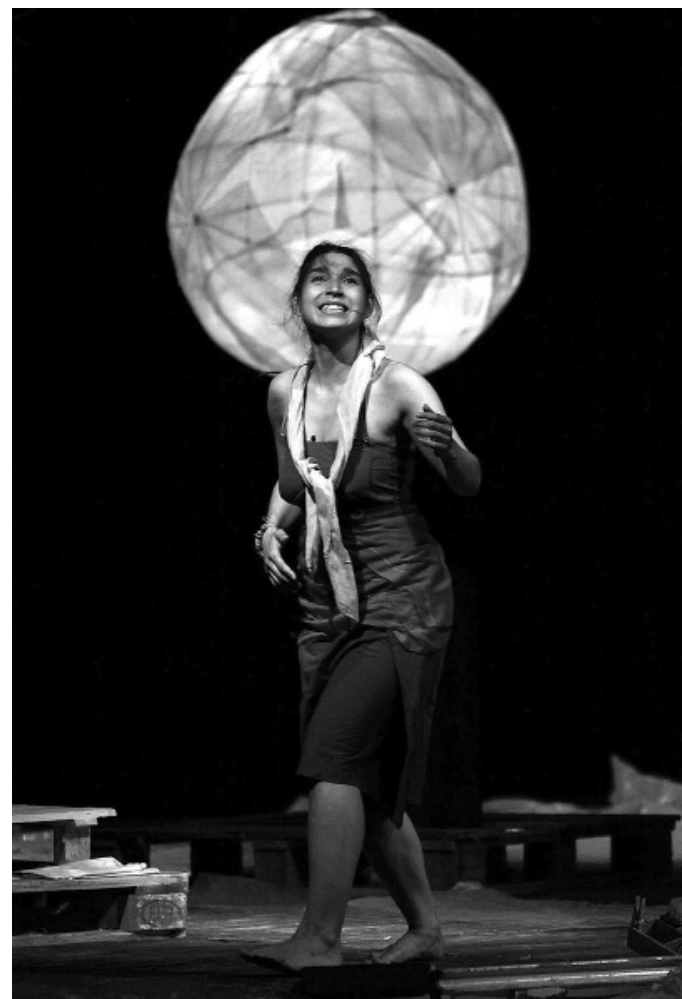

música de Nick Cave e Warren Ellis, a cenografia engenhosa e inteligente da versão cénica de Metamorfose, de Kafka (a perspectiva aérea do quarto de Gregor Samsa encurralando a estranheza de um ser desumanizado, obriga o actor Gisli Örn Gardarsson a trepar paredes com uma agilidade física estonteante) torna-se, em Fausto, uma verdadeira festa de efeitos especiais. Neste espectáculo, parte da acção desenvolveu-se numa rede gigante colocada por cima da cabeça dos espectadores, houve demónios acrobáticos, estouros e fumos. A aposta no dispositivo cénico foi prosseguida pelo finlandês Kristian Smeds, que adaptou Mr. Vertigo de Paul Auster, colocando os espectadores no palco giratório. Um drama em estações levou o público a girar enquanto seguia as etapas do percurso sacrificial de Walt, sujeito à crueldade de um Mestre que ensina a arte da levitação. Mais impressionante - pelo envolvimento musical e pela atmosfera misteriosa - do que compreensível, o espectáculo dispersou-se em capítulos e efeitos. 0 fraco domínio da língua finlandesa não ajudou.

A mestria técnica ficou patente nos espectáculos de Moguchiy, representante do teatro contemporâneo russo e fundador do teatro Formalny (1990), e de Lev Dodin, vencedor do VIII Prémio Europa. Com orquestra ao vivo, Moguchiy cruzou video, cenografia bidimensional e enormes figuras tridimensionais para contar a história de uma família em Felicidade, a partir de textos de Maeterlinck. A experimentação e a audaciosa sintese de formas teatrais têm sido o apanágio deste encenador amplamente reconhecido. Já Dodin, director artístico do Teatro Maly e mestre de várias gerações de actores, apresentou As três irmãs, de Tchekov, sem efeitos, adaptações ou novas versões. A tragédia passava-se no rosto, transparecia na imobilidade dos corpos, enquanto as palavras se soltavam em modulações suaves, ínfimas, precisas. Uma contenção crescente implodia num silêncio desesperado ou sem qualquer esperança. Nesse espectáculo, assistimos à devoção, quase religiosa, dos actores à sua arte. Uma arte do desaparecimento, pela qual os intérpretes se fundem na palavra e num colectivo dedicado a uma missão maior do que os indivíduos. Só deste modo o teatro é uma nova realidade, sempre inovadora e original.

\section{Referência bibliográfica}

IDEN, Peter (2011), "Symposium", in Catálogo do 14 Prémio Europa.
Contos em viagem,

Cabo Verde, enc. Miguel Seabra Teatro Meridional, São Petersburgo, Teatro Kommissarzhevskaya, 2011 (Carla Galvão), fot Luciano Rossetti $\odot$ Phocus Agency. 